www.ijpsonline.com

\title{
Comparative Efficacy and Safety of High-viscosity versus Low-viscosity Bone Cement in the Treatment of Osteoporotic Vertebral Fractures
}

\author{
ZHI YU AND H. SENDONG* \\ Department of Orthopeadics, Zhongda Hospital Southeast University, Jiangbei, Nanjing, Jiangsu, PR China
}

Yu et al.: Efficacy and Safety Comparison of Low-viscosity Bone Cement

\begin{abstract}
This study was to compare the clinical effects of high-viscosity with low-viscosity bone cement in percutaneous vertebroplasty for the treatment of osteoporotic vertebral fracture. A total of 112 patients with osteoporotic vertebral fracture received percutaneous vertebroplasty treatment from March 2015 to March 2017 in the Zhongda Hospital Southeast University were enrolled and divided into the high-viscosity group (n=56) and low-viscosity group $(n=56)$ according to the cement used. Visual analogue scale, Oswestry disability index, Cobb angle and leakage were observed before operation, 2 days after operation and 4 months after operation. There was no significant difference in visual analogue scale score, Oswestry disability index score or Cobb angle between the 2 groups before operation. However, the visual analogue scale score, Oswestry disability index score and Cobb angle of the high-viscosity group were lower than those of the low-viscosity group $2 \mathrm{~d}$ after operation and 4 months after operation. Besides, the proportion of leakage into the venous area, intervertebral area, paravertebral area and the total leakage rates in the high-viscosity group were lower than those in the low-viscosity group. In conclusion, compared to the low-viscosity bone cement, the high-viscosity bone cement could significantly relieve the postoperative pain, restore the height of vertebrae and reduce the venous, intervertebral and paravertebral leakage rate. Therefore, high-viscosity bone cement can be used as the first choice for the treatment of osteoporotic vertebral fracture.
\end{abstract}

Key words: High-viscosity bone cement, low-viscosity bone cement, OVF, percutaneous vertebroplasty

Twenty percent of the osteoporosis (OP) patients over 70 y age suffer from osteoporotic vertebral compression fractures (OVF) of different degrees ${ }^{[1]}$. With the rapid growth of the aging population, the $\mathrm{OP}$ and the resulting fractures are becoming more and more frequent, which seriously affect the quality of life and the health of the elderly. In particular, OVF is considered to be a precursor to the deterioration of health of the elderly ${ }^{[2]}$. Percutaneous vertebroplasty (PVP) is an effective and minimally invasive technique for the treatment of $\mathrm{OVF}^{[3,4]}$. PVP can restore the stability of the vertebrae, the Cobb angle, and improve the quality of life of the patients. However, the incidence of bone cement leakage can reach to 30-70 \% after PVP. In fact, paravertebral leakage can cause nerve damages and venous leakage can cause fatal complications, such as pulmonary embolism $^{[5,6]}$. The viscosity of the bone cement is one of the main reasons to avoid the leakage of the cement ${ }^{[7]}$. At present, there is no consensus on how to reduce the leakage of bone cement. Some scholars ${ }^{[8,9]}$ have applied the high-viscosity bone cement to reduce the incidence of bone cement leakage, but still no one has drawn a reliable conclusion. In order to further explore whether the effectiveness and safety of the high-viscosity bone cement is greater than that of the low-viscosity bone cement, patients underwent PVP surgery from March 2015 to March 2017 in Zhongda Hospital Southeast University were enrolled and divided into the highviscosity group and low viscosity group according to the cement applied and the effectiveness and safety of PVP in these 2 groups were analyzed to provide reference for the application of bone cement in PVP surgery.

A total of 112 patients (62 male and 50 female, aged 54 to $79 \mathrm{y}$, with an average age of $67.5 \pm 2.1 \mathrm{y}$ ) with OVF, who received PVP treatment from March 2015 to March 2017 were enrolled. Inclusion criteria were, 1. the clinical symptoms and imaging results meet with the diagnostic criteria of OVF; 2. patients are who are either 50 y old or above; 3 . VAS score are equal to or greater than 5 points; and 4. those who gave signed informed consents to participate in this study. While the exclusion criteria were, 1. patients who refused 
to participate in the study; 2 . patients with injury in spinal cord or nerve; 3 . patients with vertebral fractures caused by pathological diseases; 4 . patients who cannot tolerate PVP in general conditions; and 5. patients with infection or dysfunction of coagulation function at the site of puncture. Those patients were divided into the high-viscosity group $(\mathrm{n}=56)$ and low-viscosity group $(n=56)$ according to the bone cement used. There was no significant difference in the general conditions between both the groups, as shown in Table 1 .

The patients were prone to lie on the 4 point scaffold in spinal surgery, suspended in the chest and abdomen. The fractured vertebrae area was locally anesthetized with $1 \%$ lidocaine after finishing the location procedure using the $\mathrm{C}$-arm X-ray machine. The puncture needle was inserted to the proper position of the fractured vertebrae through the pedicle of the vertebral arch. When the position was confirmed by the C-arm X-ray machine, the prepared polymethyl methacrylate (PMMA) bone cement would consistently be injected into the vertebrae by a special injector and special hydraulic propulsion under the monitor of the above machine. The injection volume was $2.5 \sim 5.0 \mathrm{ml}$ and the average of which was $2.5 \pm 1.0 \mathrm{ml}$. The injection position was located in the central front $(1 / 3)$ of the vertebrae. PALACOSR $+\mathrm{G}$ high-viscosity PMMA bone cement (Heraeus Medical GmbH, Germany) was used in the high-viscosity group and MENDEC spine lowviscosity PMMA bone cement (Tecres SPA, Italy) was applied in the low-viscosity group.

Spinal X-ray examinations were conducted in $2 \mathrm{~d}$ after operation and the patients received spinal X-ray examinations and CT examinations on discharge postoperatively, which aimed at evaluating the distribution of the bone cement and whether bone cement leakage occurred. The assessments were conducted by two diagnostic imaging specialists and discussions would be held when there were different opinions. Visual analogue scale (VAS) was used to evaluate the lumbago changes before, $2 \mathrm{~d}$ and 4 mo after operation. The Oswestry function index (ODI) was used to evaluate the lumbar function. Meanwhile, the X-ray examinations of the spinal column were performed and the incidence of adjacent vertebral fractures was evaluated.

All data were analysed using SPSS 21.0. VAS, ODI and Cobb angle were analysed by repeated analysis of variance at different time periods after operation. The paired-t test was used between the two groups. Chisquare test was applied in the analysis of leakage rates of the two groups. $\mathrm{p}<0.05$ showed that the difference was statistically significant.

There was no significant difference between the 2 groups in VAS scores before surgery. However, there was significant difference in VAS score of the 2 groups in $2 \mathrm{~d}$ and 4 mo after operation. In particular, The VAS score of high-viscosity group was lower than that of low-viscosity group, as shown in Table 2. No significant difference was observed between the 2 groups in the ODI scores before operation. However, statistically significant difference was observed in ODI scores of the 2 groups in $2 \mathrm{~d}$ and 4 mo after operation. Specifically, the ODI scores of the high-viscosity group were lower than that of the low-viscosity group, as shown in Table 3.

There was no significant difference in the preoperative Cobb angle between the two groups. However, the Cobb angle of the high-viscosity group was lower than that of the low-viscosity group in $2 \mathrm{~d}$ and 4 mo after operation, as shown in Table 4.

TABLE 1: COMPARISON OF GENERAL CHARACTERISTICS IN THE TWO GROUPS

\begin{tabular}{|c|c|c|c|c|}
\hline Parameter & High-viscosity group, $(n=56)$ & Low-viscosity group, $(n=56)$ & $t / X^{2}$ & $\mathbf{P}$ \\
\hline Male/female & $30 / 26$ & $31 / 25$ & 0.036 & $>0.05$ \\
\hline Age $(y)$ & $67.8 \pm 2.6$ & $66.9 \pm 2.4$ & 1.45 & $>0.05$ \\
\hline $\mathrm{BMI}\left(\mathrm{kg} / \mathrm{m}^{2}\right)$ & $24.1 \pm 2.7$ & $24.2 \pm 2.4$ & 0.67 & $>0.05$ \\
\hline Course of disease (day) & $4.6 \pm 2.1$ & $4.4 \pm 1.8$ & 1.03 & $>0.05$ \\
\hline Operation time (min) & $46.9 \pm 8.2$ & $45.6 \pm 7.5$ & 1.14 & $>0.05$ \\
\hline Injection volume $(\mathrm{ml})$ & $3.5 \pm 0.4$ & $3.4 \pm 0.7$ & 0.58 & $>0.05$ \\
\hline
\end{tabular}

TABLE 2: COMPARISON OF THE VAS SCORES IN THE TWO GROUPS

\begin{tabular}{|c|c|c|c|c|c|c|}
\hline Group & $n$ & Before operation & $2 \mathrm{~d}$ after operation & 4 mo after operation & $F$ & $\mathbf{P}$ \\
\hline High-viscosity group & 56 & $18.2 \pm 1.1$ & $3.3 \pm 2.2$ & $2.1 \pm 0.6$ & 21.75 & $<0.05$ \\
\hline Low-viscosity group & 56 & $18.3 \pm 0.9$ & $4.5 \pm 1.7$ & $3.1 \pm 0.5$ & 24.29 & $<0.05$ \\
\hline $\mathrm{t}$ & & 0.46 & 5.07 & 6.48 & & \\
\hline$P$ & & $>0.05$ & $<0.05$ & $<0.05$ & & \\
\hline
\end{tabular}


Ninety five and 96 segments were treated in the highviscosity group and low-viscosity group, respectively. Statistically significant differences were observed in the proportions of the leakage into the venous area, intervertebral area, paravertebral area as well as the total leakage rates, with all the above values lower in the high-viscosity group when compared to the lowviscosity group. The detailed data were shown in Table 5.

Traditional operation methods for OVF mainly included the posterior pedicle internal fixation and fixation of injured vertebrae ${ }^{[10]}$. Two pedicle screws are inserted into both sides of the adjacent vertebra of the injured vertebrae in a posterior pedicle internal fixation, with the aim to indirectly restore the injured vertebrae with the help of the anterior and posterior longitudinal ligaments and the adjacent intervertebral disks of the injured vertebrae. The procedure is simple and can fix the spine and have less influence on the spine. Besides, it can restore the height of the injured vertebrae. However, the procedure could not restore the complete structure of the trabecular bone, leading to the formation of the eggshell shaped vertebrae ${ }^{[11]}$. Compared with the traditional open surgery, PVP under C-arm fluoroscopy can bring less trauma, promote faster recovery and have less influence on the cardiorespiratory function of patients. As a result, it has become the mainstream choice nowad ${ }^{[12,13]}$. For patients with OVF, PVP operation should be performed immediately when OVF occurred so as to relieve the lumbago and back pain, restore their daily life and reduce the complications related to bedridden status. The results of this study showed that the VAS scores of the 2 groups improved significantly in $2 \mathrm{~d}$ and 4 mo after operation, with more obvious changes occurred in the high-viscosity group, and the same trends were observed in the ODI scores. The main reason is that lowviscosity and high-viscosity bone cement have the same mechanism in relieving lumbago caused by OVF. PVP treatment can improve the thermochemical damage to nerve terminals after OVF and the mechanical stability of the whole vertebrae is enhanced after the application of bone cement. Previous studies ${ }^{[14]}$ have pointed out that the efficacy of low-viscosity bone cement and high-viscosity bone cement is comparable in the treatment of OVF. Whereas, the incidence of venous leakage and paravertebral leakage with low-viscosity bone cement is high as well as fatal ${ }^{[15]}$. Bone cement leakage can damage the nerve root, lead to pulmonary embolism, or even death. Therefore, the reduction of PVP leakage has become the focus of researchers. Although gelatin sponge has been applied to the vein embolization in the vertebrae ${ }^{[16]}$, which can reduce the venous leakage, it will lengthen the operation time and increase the operation difficulty, thus limiting the clinical application. The viscosity of the bone cement is the main factor affecting the leakage from the veins. This study found that high-viscosity bone cement can reduce the venous leakage, vertebral leakage and

TABLE 3: COMPARISON OF ODI SCORES IN THE TWO GROUPS

\begin{tabular}{|c|c|c|c|c|c|c|}
\hline Groups & $\mathrm{n}$ & Before operation & Postoperative $2 \mathrm{~d}$ & Postoperative $4 \mathrm{mo}$ & $F$ & $\mathbf{P}$ \\
\hline High-viscosity group & 56 & $82.7 \pm 8.2$ & $24.5 \pm 3.6$ & $22.3 \pm 2.5$ & 32.48 & $<0.05$ \\
\hline Low-viscosity group & 56 & $83.1 \pm 9.4$ & $27.3 \pm 3.2$ & $26.8 \pm 3.4$ & 25.16 & $<0.05$ \\
\hline $\mathrm{t}$ & & 0.61 & 4.92 & 5.16 & & \\
\hline $\mathrm{P}$ & & $>0.05$ & $<0.05$ & $<0.05$ & & \\
\hline
\end{tabular}

TABLE 4: COMPARISON OF THE CHANGES IN COBB ANGLE IN THE TWO GROUPS OF PATIENTS

\begin{tabular}{lcccccc}
\hline Groups & $\mathrm{n}$ & before operation & postoperative 2 d & postoperative 4 mo & $\mathrm{F}$ & $\mathrm{P}$ \\
\hline High-viscosity group & 56 & $27.3 \pm 3.7$ & $15.5 \pm 1.7$ & $14.8 \pm 1.9$ & 22.7 & $<0.05$ \\
Low-viscosity group & 56 & $27.5 \pm 3.4$ & $20.3 \pm 2.2$ & $18.4 \pm 2.3$ & 24.5 & $<0.05$ \\
$\mathrm{t}$ & & 0.51 & 5.16 & 6.74 & & \\
$\mathrm{P}$ & & $>0.05$ & $<0.05$ & $<0.05$ & & \\
\hline
\end{tabular}

TABLE 5: COMPARISON OF POSTOPERATIVE BONE CEMENT LEAKAGE RATE IN THE TWO GROUPS

\begin{tabular}{lcccccc}
\hline Groups & $\mathrm{n}$ & Segments & Venous leakage & $\begin{array}{c}\text { Intervertebral } \\
\text { leakage }\end{array}$ & $\begin{array}{c}\text { Paravertebral } \\
\text { leakage }\end{array}$ & Total leakage \\
\hline High-viscosity group & 56 & 96 & $7 / 96(7.3 \%)$ & $7 / 96(7.3 \%)$ & $8 / 96(8.3 \%)$ & $22 / 96(22.9 \%)$ \\
Low-viscosity group & 56 & 95 & $22 / 95(23.2 \%)$ & $26 / 95(27.4 \%)$ & $15 / 95(15.6 \%)$ & $63 / 95(66.3 \%)$ \\
$X^{2}$ & & & 8.34 & 10.17 & 5.26 & 11.08 \\
P & & & $<0.05$ & $<0.05$ & $<0.05$ & $<0.05$ \\
\hline
\end{tabular}


paravertebral leakage rates. The reason may be that high-viscosity bone cement can increase the viscosity between the bone tissue and the material and thus reduce the leakage rate. Compared to the low-viscosity bone cement, high-viscosity bone cement can be evenly distributed in the vertebrae, thereby reducing the leakage rates.

Compared to the low-viscosity bone cement, highviscosity bone cement can significantly relieve the postoperative pain, restore the height of vertebrae and reduce the incidences of venous leakage, intervertebral leakage and paravertebral leakage, which can be used as the first choice for the treatment of OVF.

\section{Conflict of interest:}

\section{There was no conflict of interest.}

\section{REFERENCES}

1. En X, Hao DJ. Percutaneous kyphoplasty versus conservative treatment in acute and subacute osteoporotic vertebral compression fractures (OVF): a double-blinded, randomized controlled clinical trial (RCT) in the population of western China. Spine J 2013;13:S90-1.

2. Liang L, Chen X, Jiang W, Li X, Chen J, Wu L, et al. Balloon kyphoplasty or percutaneous vertebroplasty for osteoporotic vertebral compression fracture? An updated systematic review and meta-analysis. Ann Saudi Med 2016;36:165-74.

3. Hu YM, Pang QJ. Effectiveness of manipulative reduction combined with minimally invasive surgery in the treatment of osteoporotic vertebral compression fracture: a meta-analysis. Chin J Orthop Traumatol, 2015;28:1042-7.

4. Hong-De Li CJ, Wang $\mathrm{H}$, Liu W, Jiang XJ, Zhu XQ. Percutaneous vertebroplasty for single osteoporotic vertebral body compression fracture: results of unilateral 3-D percutaneous puncture technique. Indian $\mathrm{J}$ Orthop 2015;49:245-50.

5. Wang YW, Ni C F, Chen L. Clinical application of percutaneous vertebroplasty and kyphoplasty in treating malignant tumors of spine. J Intervent Radiol 2012;58(4):471-87.

6. Zhu SY, Zhong ZM, Wu Q, Chen JT. Risk factors for bone cement leakage in percutaneous vertebroplasty: a retrospective study of four hundred and eighty five patients. Int Orthop 2016;40:1205-10.

7. Zhao L, Wang L, Wang $\mathrm{G}$, $\mathrm{Xu}$ J, Zeng $\mathrm{Y}$, Zheng $\mathrm{S}$, et al. Prevention and treatment of bone cement leakage in percutaneous kyphoplasty for osteoporotic vertebral body compression fracture. Zhongguo Xiu Fu Chong Jian Wai Ke Za Zhi 2009;23:404-7.

8. Liu T, Li Z, Su Q, Hai Y. Cement leakage in osteoporotic vertebral compression fractures with cortical defect using high-viscosity bone cement during unilateral percutaneous kyphoplasty surgery. Medicine (Baltimore) 2017;96:e7216.

9. Anselmetti GC, Zoarski G, Manca A, Masala S, Eminefendic $\mathrm{H}$, Russo $\mathrm{F}$, et al. Percutaneous vertebroplasty and bone cement leakage: clinical experience with a new high-viscosity bone cement and delivery system for vertebral augmentation in benign and malignant compression fractures. Cardiovasc Intervent Radiol 2008;31:937-47.

10. Zhang ZM, Liu J, Zhang YN, Wang YF, Huang CX. Treatment of atlanto-axial vertebral instability fractures with cervical posterior pedicle screw internal fixation and interbody fusion. Zhongguo Gu Shang 2014;27:762-5.

11. Wei W, Xiao Z, Lu W, Mai Y, Huang C, Hua S. Spinal pedicle screw internal fixation through endoscope-assisted posterior approach for treatment of traumatic atlantoaxial instability. Zhongguo Xiu Fu Chong Jian Wai Ke Za Zhi 2012;26:1324-9.

12. Wang H, Sribastav SS, Ye F, Yang C, Wang J, Liu H, et al. Comparison of percutaneous vertebroplasty and balloon kyphoplasty for the treatment of single level vertebral compression fractures: a meta-analysis of the literature. Pain Physician 2015;18:209-2.

13. Zhang L, Liu Z, Wang J, Feng X, Yang J, Tao Y, et al. Unipedicular versus bipedicular percutaneous vertebroplasty for osteoporotic vertebral compression fractures: a prospective randomized study. BMC Musculoskelet Disord 2015;16:145.

14. Zhang L, Wang J, Feng X, Tao Y, Yang J, Wang Y, et al. A comparison of high viscosity bone cement and low viscosity bone cement vertebroplasty for severe osteoporotic vertebral compression fractures. Clin Neurol Neurosurg 2015;129:10-6.

15. Dohm M, Black CM, Dacre A, Tillman JB, Fueredi G. A randomized trial comparing balloon kyphoplasty and vertebroplasty for vertebral compression fractures due to osteoporosis. AJNR Am J Neuroradiol 2014;35:2227-36.

16. Shen Y, Liu F, Zhang Y. Outcomes of unilateral or bilateral percutaneous kyphoplasty for osteoporotic vertebral compression fractures. Chin J Spine Spinal Cord 2011;21:2026.

This is an open access article distributed under the terms of the Creative Commons Attribution-NonCommercial-ShareAlike 3.0 License, which allows others to remix, tweak, and build upon the work non-commercially, as long as the author is credited and the new creations are licensed under the identical terms

This article was originally published in a special issue,
"XXXXXX"
Indian J Pharm Sci 2020:82(1)spl issue1;XX-XX

